\title{
A First Experience of Using Failure Report as a Reflective Tool in Engineering Education
}

\author{
https://doi.org/10.3991/ijet.v16i18.24271
}

\author{
Ahmad Salahuddin Mohd Harithuddin \\ Universiti Putra Malaysia, Selangor, Malaysia \\ a_salahuddin@upm.edu.my
}

\begin{abstract}
The paper reports the first use of failure report as a reflective learning tool in engineering education from a university in Malaysia. Failure Report is a document that publishes and discusses failures as part of a reflective learning process for students. This reflective learning method attempts to encourage students to actually learn from failure and to take negative experiences as a learning opportunity. This paper describes the experience of introducing Failure Report as a means for engineering students to reflect their learning after completing an engineering design project. The Gibbs' Reflective Learning Model is used as the base of the reflective work. This introductory study reveals some findings on how students view and reflect on their failures and setbacks during the project work. It is noted that this was their first ever experience in doing a reflection study. Most of the students' writing revolves around interpersonal skills like teamwork and communication. The element of 'blame game' is prevalent in their reports. In addition, based on this first experience, we provide several principles to follow to replicate the Failure Report activity and further recommendations for future failure reflection work.
\end{abstract}

Keywords-reflective learning, failure report, engineering education, lifelong learning

\section{Introduction}

Trial-and-error is a fundamental process of learning and discovery. However, the 'error' part is rarely looked at and left out in the process of learning. The need to learn from failure is incontestable, however, the ' $\mathrm{f}$ ' word is stigmatized. Learning from failure is often encouraged in words, but rarely students were given the chance to practice. This work attempts to formalize learning-from-failure as a learning activity and observe students' response when asked to reflect on specifically their negative experiences in learning.

Failure is part of the process whether it is an engineering design process or the learning itself. Though experimentation and risk-taking attitude are always preached as attributes of a proper engineer, engineering activities - such as design reports - "often focus on successful designs and overlook failed ones" [1]. The ability to learn from failure, especially where creativity elements are involved, is a common wisdom but 
engineering curricula "lack instruction and assessment frameworks that encourage creativity in the classroom" [2]. This results in engineering graduates with reduced risktaking attitudes [3] that is, they usually look into tried-and-tested solutions instead of trying to innovate. The neglect of creativity encouragement in curriculum can result in senior-level engineering students becoming less creative than their freshmen counterparts [4]. Though analysis of failure in engineering design (e.g. [5]) are common, reflecting learning on the affective domain, for example, team work and organizational communication are still lacking. We believe that by allowing students to fail and reflectively learn from it can foster creativity and innovation in engineering education [6]. Learning from failure is paramount but the existing stigma about failing perhaps can make the learning process not conducive to experimentation and discovery.

How do we formalize learning from failure? One way is to make it part of the assessment in class. A natural approach is to use reflective writing where the final deliverable can be a type of reflection report. Engineering report focusing on negative results and experiences is relatively rare in practice, however, some relevant examples can be found. Engineering Without Borders, Canada (EWB-Ca) is one of the first organization to document their project failures in their Annual Report, and has been producing Failure Reports yearly since then [7]. EWB-Ca also has been maintaining a website (https://www.admittingfailure.org/) dedicated as a resource for learning from failure as an organization.

The realm of scientific research and academia has taken a serious look at this concept of negative results [8]-[10]. This stems from the 'file drawer problem', which refers to the fact many negative results remain unpublished, creating publication bias. Several journals are dedicated in reporting negative results - delivered by studies that "failed" to prove the hypothesis - in correcting publication bias. One example is Missing Pieces (https://collections.plos.org/missing-pieces), a PLOS ONE collection focusing on the publication of negative, null and inconclusive results. Another example is the Journal of Trial and Error or JOTE (https://www.jtrialerror.com/) which aims to make failures known to other researchers in the field.

The implementation of Failure Report as a learning tool is inspired by these publications. Instead of producing the traditional engineering report that tells the story of positive results and success, we implore students to reflect on the bad experience and actually learn from the negatives. Implementing this idea in classroom, to the knowledge of the authors, is new. Thus, it is only natural for an inquisitive mind to experiment with this method and study the outcome.

This study is explorative in nature and approached qualitatively. This is imperative in order to examine the outcomes of writing failure reports as a tool of experiential learning. A class of 35 third-year aerospace engineering students was given a task involving a design project. Starting from this experience, the students were asked to write a reflection about their learning experience - focusing on failures instead of successes. Reflection is obtained from the student's written reports, feedback during discussions and interviews. A thematic analysis is then carried out on the data to identify the themes that relate to initial experience of students towards the introduction of failure report as a form of experiential learning. 


\section{Approach}

The objective here is to formalize learning-from-failure through reflection. The unique twist here is that the reflection report is only looking towards the negative experiences, setbacks or deficiencies from their learning activities, and hence will be called a Failure Report. The plan is therefore to make Failure Report as one of the course assessments. Failure Report starts with an introduction of a complex engineering design project with little to no guidance where the students will most likely fail to solve. The idea is to use the experience of solving the problem - especially the negative ones - to help them start a reflective work. After the project, a series of sessions will be conducted to discuss about the experience and guide the students on writing the Failure Report. Textual data is collected and analyzed qualitatively to observe common themes.

\subsection{Aligning of Graduate Attributes with Learning Outcome}

Graduate attributes, or program outcomes, is described as the knowledge, skills and attitudes that engineering students are expected to know, perform or attain by the time of graduation. Two of the twelve listed outcomes in [11] that are set for this course are (i) design and development of solutions and (ii) life-long learning. 'Design/Development of Solutions', an attribute defined by the Engineering Accreditation Council of Malaysia as the ability to "design solutions for complex engineering problems and design systems, components or processes that meet specified needs with appropriate consideration for public health and safety, cultural, societal, and environmental considerations". 'Lifelong Learning', defined as the ability to "recognize the need for, and have the preparation and ability to engage in independent and life-long learning in the broadest context of technological change" [11].

How can an engineering design problem be used to design a learning-from-failure instruction? Design problems, in general, are often characterized as being ill-defined and having multiple or no solution. In the pursuit of an optimal solution to the problem, design iterations are often employed to correct errors and ultimately to lead solvers to better solutions [12]. Here lies a potential source of failures on which students can do a reflection. Furthermore, solving complex problems always involves collaboration of many people [13]. This adds another dimension of complexity in the activity in which we can find more sources of failure. Generally, the routes towards finding solutions to a complex problem itself is an adventurous process that can be a rich learning experience.

Additionally, the ability to reflect learning experiences and critically evaluate them in order to gain new insights is part of the process of life-long learning [14]. Thus, we also believe that, under the philosophy of constructive alignment [15], to reflectively learn from design failures does indeed address the intended course outcomes.

\subsection{Assessment Design}

In order for an assessment to be effective, it has to be linked with the learning outcome and the program outcome set earlier. This is to ensure that the intended 
knowledge, skills, and attribute are being assessed using appropriate method. The assessment is designed to be a formative one where the focus is to develop life-long skills and competencies to address failure as opportunities to improve oneself.

The class were given a task to design an attitude control system with the purpose to control the flight orientation of a space vehicle with long body, i.e., rocket. Though the task is broadly defined, the problem required depth of analysis in the sense that it has no one "right" solution and requires originality on creating a suitable model that fits the objective of the task. The students were asked to develop and prototype the solution and make design revision based on the solution chosen.

The class were given the task in the second week of the semester. The students are divided into groups. Each group includes four or five people and led by a group manager. Each group is responsible for particular aspect of the project management, for example, "Design \& Manufacturing", "Electronics", "Coding", "Finance". One student is selected from the class to be the chief engineer coordinating the groups and handling weekly reports and presentations.

The problem-solving process is designed to end with failure - where students unable to come up with a solution. The project is halted mid-way and a reflective study is conducted through a series of class sessions until the end of the semester. A complete failure report is produced by each student at the end.

\subsection{Gibbs Reflective Learning Cycle}

Learning from past experience is the core definition of reflective learning. In the Failure Report activity, we wanted the student to pay critical attention to past failures and deliberately reflect on their experiences in hoping that they will gain self-developmental insights [16][17]. The deliberate reflection took the forms of post-mortem discussion and writing individual reports so that the discourse is conducted both verbally and in writing.

Numerous models of reflection have been created to guide experiential learning in classrooms. Notable examples are the What? So what? Now what? method [18][19], the Johns Model of Reflection [20], and the 5R reflection framework [21]. We adopted the experiential learning model employing Gibbs' reflective cycle [22] due to its emphasis on emotions and attitudes, which may be more suitable for describing experience rather than the engineering technicalities. We believe that such an unorthodox engineering report can be used to assess engineering students' affective domain. The framework provides a method with distinct stages and clear questions for students to selfassess their experience.

The Gibbs Reflective Learning Cycle includes six stages of reflection which begins with an experience of some kind. The stages are to be sequentially worked with a set of questions to guide the learner throughout the cycle. The cycle is depicted in the Figure 1. 


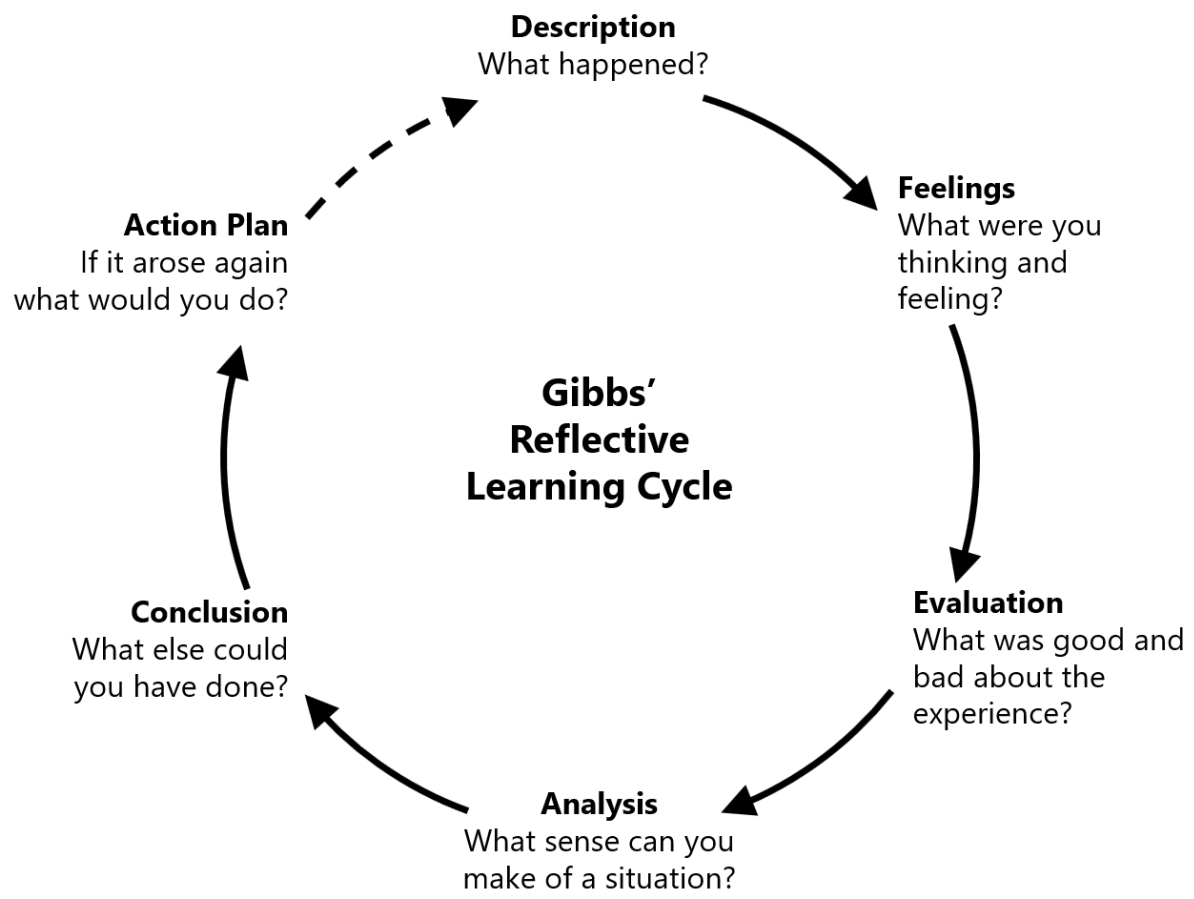

Fig. 1. Gibbs' Reflective Learning Cycle [22]

In the first stage 'Description' students describes the experience of their learning to the reader. In the next stage, 'Feelings', students describe their feelings and thoughts about the learning experience itself. The next stage, 'Evaluation' requires the student to assess the experience; what went well and what went wrong. 'Analysis' asks the students to make sense of the situation by asking why it went well/wrong. The 'Conclusion' stage asks the students about what they would do differently about their previous experience. In the final stage, the 'Action Plan', the students consider on what their response would be if they encounter similar situations in the future. The process goes on when students deal with a similar learning experience again.

Sticking with the theme of learning from failure, students were instructed to focus more on the negative experience - setbacks, problems, and other unfortunate development - that happened during the completion of the assignment. In conjunction with this strategy, in stage 3 of the reflection, Evaluation, we specifically asked 'what went wrong' and focused on reflecting on bad experiences.

\subsection{Administering the Final Report Activity}

The students were informed about the Failure Report on the tenth week (about twothirds of the semester). At this stage the students mostly have chosen a solution but were still in design revision process. The project is halted and a post-mortem discussion was conducted to evaluate the outcome of the project and on their design experience. 
In this post-mortem session, the idea of publishing an individual Failure Report was conveyed. A supportive environment can be established by showing models of good work [23]. Therefore, two existing examples of Failure Reports from Engineering Without Borders were given to students. These two examples are available online [24][25].

At the end of the post mortem, we asked students for reflection by writing less-than400 -words paper specifically on the failures and setbacks in the project. To help students with the reflective writing, they were each given a worksheet on the Gibbs Reflection Learning Cycle as shown on Figure 1 and were asked to share their thoughts with the class. This paper is treated as their rough drafts of the Failure Report.

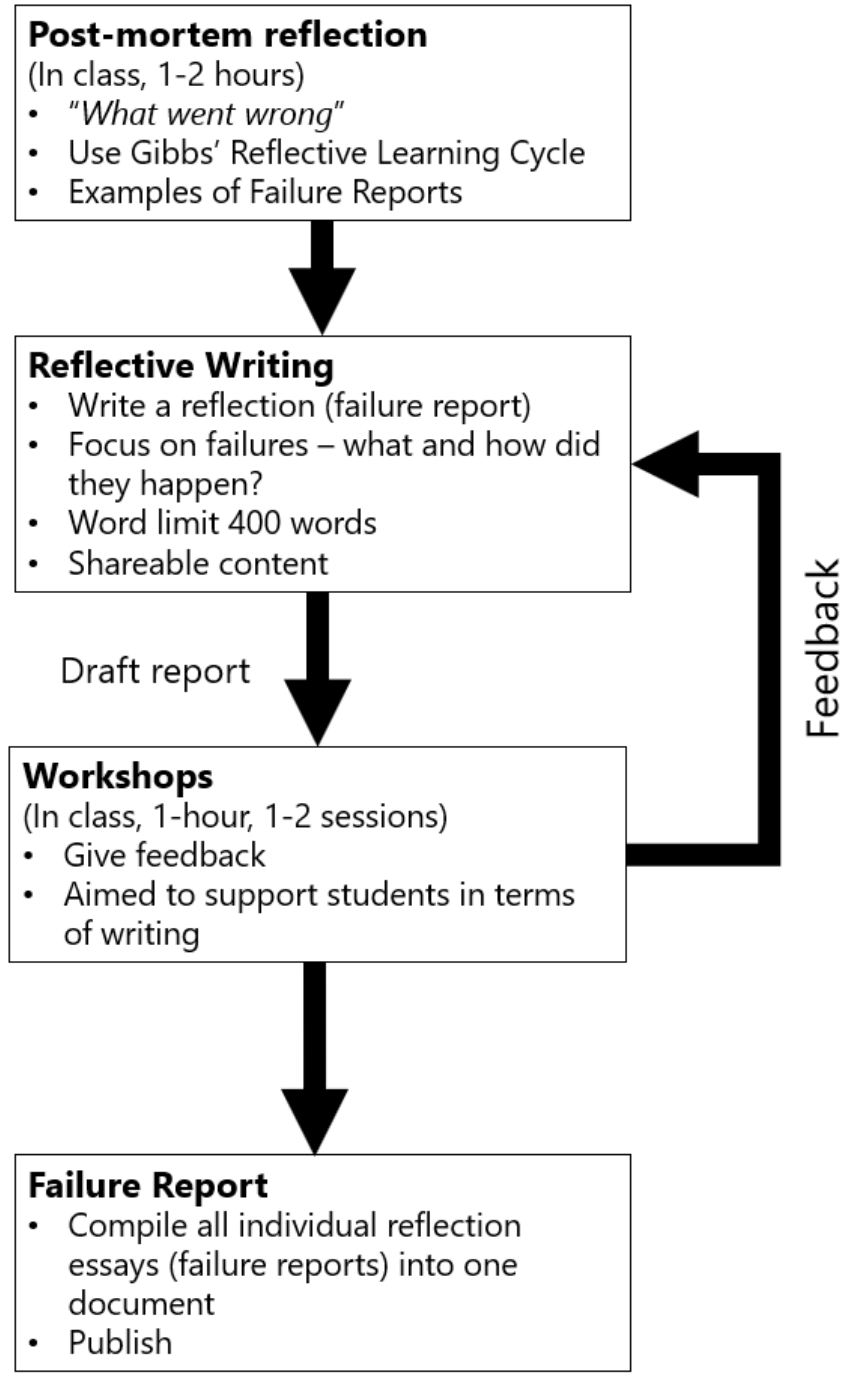

Fig. 2. Conducting Failure Report Workshop 
To support the students even more, the rough drafts were collected and evaluated. The purpose is to make sure that the 'failure' aspects were clearly described (why it was a failure) and the word limit is adhered to. These drafts from students were shared with the class in a few short workshop sessions. These workshops were intended to support students in terms of writing failure reports and to be a platform for sharing the reports among the members of the project. The sharing intended to make students to work to understand the perspective of other members of the class to their story. The students were provided chances for revision and resubmission of drafts. As the final deliverable, a 400-word individual failure report was required.

After compiling and publishing the Final Reports, students were asked to again reflect and give feedback on the Failure Report exercise. The overall procedure is presented in a flowchart form in Figure 2.

About a month after the publication of the final Failure Reports, students were given a chance to give a feedback on the learning experience they have obtained from the Failure Report activity. Twenty-four out of the 35 students submitted their feedback through Google Form.

\section{$3 \quad$ Findings and Analysis}

We present the results in two distinct parts. The first part is to report the findings in the reports after applying the Gibbs' reflective learning cycle model in the class activity. In the second part, we thematically categorize students' feedback and responses from interviews.

\subsection{Finding from First Drafts of Failure Report: 'Blame Game'}

The first submissions of stories revealed a lot about the dynamics of the project than the traditional technical reports typical in engineering courses. One common reaction can be observed from the first submission is the 'blame game'. Seemingly, when discussing about failures, many assigned blames on external factors (another person or situation). Here are some example quotes from the first drafts, namely from Student A, Student B, Student C, and Student D:

- "some of the members still are not done with theirs and we do not even bother to ask. We should ask other members if they need any helping hand in the first place. This caused more burden to be placed" - Student A

- "not everyone played their role in completing the tasks which resulted in this outcome. Some did not take their task seriously; procrastination occurred because members were unsure of what to be done. Then, we became dependent on specific person." - Student B

- "Most of the members of the department are busy..." - Student C

- "The passing of information from the top leaders to the team members have been very ineffective. Team leader should have given importance in guiding their teams under them." - Student D 
Elements of self-blame are common too. Three separate students - Student E, Student $\mathrm{F}$, and Student $\mathrm{G}$ - wrote

- "I was unable to divide my time equally for each commitment that I have. And due to this, my department's progress has been lagging behind and causes other department to be on hold" - Student E

- "As a project manager, I should have recognised this problem earlier and push everyone to work together more. I should have conduct meetings with chiefs and head of departments more frequently to know their actual situation and problems. Thus, more problems can be solved earlier." - Student F

- "I am expecting to write a code for this project is easy but it is not. ... I found myself moving on to the next problem at the first sign of success. Inevitably, this led to a sloppy code. Bugs would occur and frustratingly, I would go back and fix them..." - Student G

In their first drafts, students listed their problems, setbacks and weaknesses with no meaningful reflection. After feedback and a workshop station, the elements of blame in the writing seemed to be minimized. Students view failures in a more constructive way. The tone was also more 'diplomatic' compared to the previous version. Here are several quotes from the same Student A, Student B, Student C, and Student D showing this post-workshop improvement from their previous version of their report.

- "We should be more thoughtful of others when we are working on the same boat, where in the end, we can ride the boat together. If we know or feel that someone needs our help, never hesitate to offer a helping hand. Be considerate. Trust me, our help means world to them." -Student A

- "You will need everyone in your team to make a successful outcome become possible...we should give our best when completing the task and do it with a full heart. You will be mesmerized on how your effort towards the tasks by the time you reach to the successful outcome." -Student B

- "In order [for a project to be successful], a project timeline need to be planned by [everyone in] the department." - Student C

- "we should focus more on how to make our communication to be more effective. First of all, maybe we should first analyse what we are doing wrong. We should identify the bad communication skills we have been practising. The first step to overcome our downfall is admitting our mistakes... we should work on how to make out expectations clear and make them understand." - Student D

The initial self-blaming attitude has also been improved to a more positive and forward-looking resolutions. Here are some excerpts from the previous Student E, Student $F$ and Student G.

- "Time management, another thing that is crucially affecting the project implementation and that is when we realized that time management is something that needs to be written down, alerted on every single day to boost everyone's motivation towards the making of great art of work." - Student E 
- "We will now encourage interests and participations from every team member since all contributing individually to a collective success. It is important to have a great and successful communication among the teammates. It is no doubt that communication is one of the keys towards a victorious project. A successful communication happens when everyone can voice out their ideas and opinions, and they need to listen and respect one another's ideas as well." - Student F

- "Without a doubt, to be a successful programmer, you have to be confident in your own ability to learn. This is actually a fundamental life skill... If you let yourself get overwhelmed, you will always feel a pressure to catch up and feel that you never know enough. The capacity to learn is gift, the ability to learn is a skill and the willingness to learn is a choice. Failure is success if we learn from it." - Student G

\subsection{Student Responses from Reports and Feedback}

As the end-of-course closure, students were given a chance to give a feedback on the learning experience from doing Failure Report. The feedback from student was done individually using an online form. We also interviewed two students to get a more indepth insight on their experience on doing Failure Report. We have identified several recurring themes across all data. Firstly, most of the students commented that the Failure Report activity, and the reflective learning activities in general, was a new positive experience for them. Secondly, students tend to talk about how they feel about the design project - their emotions, feelings, and attitudes - rather than discussing about technicalities of design engineering. Thirdly, when asked to pinpoint the causes of their failures, the students also mainly talked about interpersonal skills, in particular on teamwork and communication. The quotes from the students are gathered from their Failure Reports and post-activity feedback, and categorized into the aforementioned three themes.

New Experience Many noted that the idea of doing a reflection of a failure is a new and positive experience. On the other hand, this can also be seen as the student's unfamiliarity with the reflective learning activity. Since the students were all from the same cohort from their freshmen year, it can be generalized that this is their first exposure towards reflective learning from failure.

Table 1. Examples of respondent's feedback noting that doing reports on failure is a new experience

\begin{tabular}{|l|l|}
\hline Respondent & Response \\
\hline$\# 1$ & "I think the failure report was a good project that I never have thought before" \\
\hline$\# 2$ & $\begin{array}{l}\text { “...made me realize that even though there is a failure, we still can make a report out of it to } \\
\text { learn the mistake that had caused the failure. This is the first time we are doing a failure re- } \\
\text { port which is actually interesting." }\end{array}$ \\
\hline$\# 5$ & $\begin{array}{l}\text { "It was a new experience for me. Normally if a project fails, we are used to just leaving it } \\
\text { aside but this time we were asked to do a report." }\end{array}$ \\
\hline$\# 17$ & $\begin{array}{l}\text { “...quite fun because it's a new thing... bizarre but cool..." } \\
\text { "At first I was shocked when [the lecturer] asked to do a failure report because we were not } \\
\text { exposed in to do it." }\end{array}$ \\
\hline
\end{tabular}


Talking About Emotions, Feelings and Attitudes When reporting on their experience, a number of students explicitly describe their feelings and demonstrate their attitudes. Examples of this are reported in Table 2. This includes the talk about 'blame game' and the students' attitude about it. Specifically, Respondent \#1 noted that it was common for everyone to "pour their true feelings" into the reflective reports.

Table 2. Examples of respondent's feedback related to feelings and attitudes

\begin{tabular}{|c|c|}
\hline Respondent & Response \\
\hline \#13 & "I am feeling good because I can express what I felt throughout handling this project." \\
\hline \#15 & "I feel humble while writing the failure report" \\
\hline \#19 & “...mixed feeling (happy, confused and stressed)" \\
\hline$\# 1$ & "The writing went well as everyone was pouring their true feelings into it." \\
\hline \#3 & “...people start to blame other people.” [blame game] \\
\hline \#22 & "I was pointing mistakes to others..." [regret] \\
\hline \#24 & “... because I wasn’t giving enough effort” [self-blame] \\
\hline$\# 17$ & "I learned how to think maturely to accept my own failures." [acceptance] \\
\hline \#10 & "If you read (the report entries) carefully the self-blaming is usually not genuine." [cynic] \\
\hline \#11 & $\begin{array}{l}\text { "I learned that you should always ask [team members] "Are you okay with this?" "Are you } \\
\text { sure you are okay with this?" ... sometimes they keep things to themselves." [caring] }\end{array}$ \\
\hline
\end{tabular}

Comments on Interpersonal Skills The students were also asked to identify the likely causes of their failures. Two common themes appear: Teamwork and Communication. The comments were in general, tend to be emotional and mostly superficial. Respondent \#10 and \#11 noted an important difference between discussing problems in meetings and written reports: writing can be a more effective way of conveying feelings without being offensive or intrusive, which always happens in a purely verbal communication. Writing is seen as a more effective method of doing reflection as compared to, for example, discussion in post-mortem meetings.

Table 3. Examples of respondent's feedback related to problems of interpersonal skills communication and teamwork

\begin{tabular}{|l|l|}
\hline Respondent & \multicolumn{1}{c|}{ Response } \\
\hline$\# 17$ & $\begin{array}{l}\text { "Obviously, everyone did their job in their own team, or at least gave some contributions at } \\
\text { the first few weeks. But hitchhikers would always exist," } \\
\text { "No proper communication among the departments." }\end{array}$ \\
\hline$\# 16$ & $\begin{array}{l}\text { "the team didn't cooperate and each other keep on bragging they did something big to the } \\
\text { team but didn't move the project forward." } \\
\text { " } \ldots \text { then communication and cooperation became dull" }\end{array}$ \\
\hline$\# 6$ & $\begin{array}{l}\text { "... it went sideways because our cooperation/teamwork is not well-built yet." } \\
\text { making them feel comfortable doing nothing, as well as feeling that there would be another } \\
\text { people which could cover their absence in the group." }\end{array}$ \\
\hline$\# 5$ & $\begin{array}{l}\text { "All the members did their task well. The responsibility of each member I felt person- } \\
\text { ally a bit low." }\end{array}$ \\
\hline$\# 10$ & $\begin{array}{l}\text { "in post-mortems [meetings] we usually don't want to be harsh or hurting other's feelings } \\
\text { [when talking about failures]. We normally look to end the awkwardness quickly. But in }\end{array}$ \\
\hline
\end{tabular}




\begin{tabular}{|l|l|}
\hline Respondent & \multicolumn{1}{|c|}{ Response } \\
\hline & $\begin{array}{l}\text { writing report, we have time to think of nice words to express my thoughts" [verbal and } \\
\text { written discourse] }\end{array}$ \\
\hline$\# 11$ & $\begin{array}{l}\text { "I think people will tell more about their issues when [the discourse] is in writing [as com- } \\
\text { pared to verbal discussion]" [verbal and written discourse] }\end{array}$ \\
\hline
\end{tabular}

\section{Discussion and Recommendation}

From the results, the engineering students have gained their first experience of producing Failure Report through a reflective writing activity. The reflective learning is based on the cyclic model based on the Gibbs' reflective learning cycle.

\subsection{Failure Report Learning Design}

The failure report can be done after every class project, or even an examination. This is in line with the initial philosophy of this innovation that is to commit to learning from experience, both success and especially failure. A considerable adjustment can be made from the guide in Figure 2.

Feedback is one of the most crucial part in this activity. From this first experience of introducing Failure Report, we learned that student might find that writing a reflection from a negative experience can be a daunting task and a totally new experience. It is perhaps beneficial to both the instructor and students to have multiple sessions for collective sharing and discussion about producing failure reports. Presenting good existing examples of failure reports can be a help in this regard.

From the end-of-course closure activity, it is found that student might have learned more soft skills, like communication, teamwork, identifying and facing failures, handling stress, and decision-making, from this activity. Apart from communication and teamwork skills, we believe that the rest are considered lifelong skills that are crucial in the professional environment.

In a way, the Failure Report adopts a teaching approach called Productive Failure [26][27]. Kapur [26] defines Productive Failure as a learning design that let students to solve a novel problem before they receive any instruction. The problem-solving process therefore will most likely end with failure (students unable to come up with a solution). The idea is to use the prior experience of solving the problem to help them learn better in the subsequent instructions that follows. In a way, the Productive Failure design can help destigmatize failure by framing it as a part of learning process.

Five lessons that we have learned from this experience of conducting Failure Report. One, to ensure that the process will end with a productive failure, the task given must be a complex problem which has no obvious solution [11]. Students will work towards an optimized solution rather than finding the correct answer. Two, the task must be challenging enough, but not demotivating. This is consistent with the suggestions from [29]. Three, a suitable reflective learning model to guide students in reflecting on their experience. In this activity, the Gibbs' Reflective Learning Cycle [22], however, other models [18]-[21] may also be used. Four, as a result from the comments of a couple of students (Student \#10 and \#11 as reported in Table 3) who noted that students tend to 
be more sincere in writing than in oral discourse, reflection, therefore is better done in writing. And lastly, Failure report may involve delivering a lot of feedback during postmortems and reflective sessions. Two reasons here: one is that students may need help in doing reflective writing especially when they are beginners; and two, the concept of focusing on failure to learn from it is admittedly quite unorthodox and alien to most students.

\subsection{Summary of Findings}

Since this is a first implementation of Failure Reports, according to the data obtained, this is also the students' first experience on this type of activity, the success - or, failure - may be still inconclusive. However, Failure Report is an activity that can potentially be a formal venue for students to actually learn from failure. It is found also that the activity is more suitable towards assessing communication skills, teamwork, and related affective domains. The reflective cycle created by Gibbs [22] provides a simple framework for beginning students and lecturers to examine and learn from experience. References on how to use this model usually are outlined with a set of questions as prompts to guide students' failure report writing. From this experience, it was observed that the students had no problem in implementing the model into their report writing.

Moon [28] warned that while reflective models, such as the Gibbs' model, can be helpful for beginning students, it may only provide "superficial form of reflection" and that the learning that resulted from that "is likely to be superficial" too. This is apparent in the examples when the students were asked to dig deeper about the causes of the failures: Teamwork and Communication. When accounting for Teamwork, the troubleshooting mostly never went beyond complaining, e.g., "the team didn't cooperate", "cooperation became dull" "cooperation/teamwork is not well-built", and "hitchhikers would always exist." Only one student independently made an Ishikawa fishbone diagram (a type of causal diagram used identify the root causes of a specific event or problem [29]. Usually used in engineering). The superficiality continues in the discussion about Communication, e.g. "No proper communication...", "communication... became dull" and "(there is) communication failure". If depth in reflection is the main focus, we suggest incorporating this reflective model with double-loop learning [30].

\section{Conclusion}

Learning from failure has become almost a mantra - an uncontestable wisdom that should be accepted by all learners. However, very seldom students are given chance to experiment and fail. How could one then learn from hardships and setbacks towards becoming a more resilient human being. The role of teachers - and their learning institutions - is to prepare a safe space and opportunity that allows for failures.

This paper describes our first experience in introducing the Failure Report format as a reflective learning tool for engineering students. This activity stemmed from an engineering design project and started towards the end of the project completion. Instead of focusing on positive results and successful design, Failure Reports reorient the student's 
perspective towards the dark side of trial-and-error learning, that is to focus on the 'error' part hoping to learn from it. The activity also has a 'side-quest', which is to provide a safe space for students for experimentation to foster more creativity among engineering students. However, in this one example it is not possible to demonstrate any improvement in creativity among the students.

The nature of this study is rather introductory and experimental. It is found the use of Gibbs' reflective learning cycle model encourages students to talk about feelings rather analyzing deeply on solving complex problems like working in teams and communication skills. However, the Gibbs' model is excellent for students beginning their reflective work. Failure Report adds another technique that can be used in classrooms as form of productive failure learning design. It is hoped that the learning tool here can be implemented as a way to actually learn from failure, and build resilience and risktaking attitudes among engineering students.

\section{References}

[1] V. Hendley, "The importance of failure," ASEE Prism, 8(2), pp. 18-23, October 1998.

[2] S. R. Daly, E. A. Mosyjowski, C. M. Seifert, "Teaching creativity in engineering courses," Journal of Engineering Education, vol. 103, no. 3, pp. 417-449, July 2014. https://doi.org/ $10.1002 /$ jee. 20048

[3] C. A. Toh, S. R. Miller, "How engineering teams select design concepts: A view through the lens of creativity," Design Studies, 38, pp. 111-138, May 2015. https://doi.org/10.1016/ j.destud.2015.03.001

[4] N. Genco, K. Hölttä-Otto, C.C. Seepersad, "An experimental investigation of the innovation capabilities of undergraduate engineering students," Journal of Engineering Education, vol. 101, no. 1, pp. 60-81, January 2012. https://doi.org/10.1002/j.2168-9830.2012.tb00041.x

[5] M. Arjomandi, B. Gibson, A. Valiyff, B. Chartier, D. Missingham, "The role of 'hands-on' practice in aerospace engineering education," in 47th AIAA Aerospace Sciences Meeting including The New Horizons Forum and Aerospace Exposition, AIAA, 2009, pp. 1-10. https://doi.org/10.2514/6.2009-763

[6] K. Kazerounian, and S. Foley, "Barriers to creativity in engineering education: a study of instructors and students perceptions." ASME. J. Mech. Des. Vol. 129, no. 7, pp. 761-768, July 2007. https://doi.org/10.1115/1.2739569

[7] Engineering Without Borders - Canada. Failure Reports. Retrieved 2 March, 2020 from https://www.ewb.ca/en/about-us/governance/annual-report/

[8] D. Fanelli, "Negative results are disappearing from most disciplines and countries," Scientometrics, vol. 90, no. 3, pp. 891-904, March 2012. https://doi.org/10.1007/s11192-011$\underline{\text { 0494-7 }}$

[9] A. Franco, N. Malhotra, and G. Simonovits, "Publication bias in the social sciences: Unlocking the file drawer," Science, vol. 365, no. 6203, pp. 1502-1505, September 2014. https://doi.org/10.1126/science.1255484

[10] A. Mlinarić, M. Horvat, and V Šupak Smolčić, "Dealing with the positive publication bias: Why you should really publish your negative results," Biochemia medica, vol. 27, no. 3, pp. 447-452, October 2017. https://doi.org/10.11613/bm.2017.030201

[11] Engineering Programme Accreditation Manual 2017, Engineering Accreditation Council, Board of Engineers Malaysia, Retrieved 2 March, 2020 from http://www.eac.org.my/web/ 
[12] R. Costa, and D. L. Sobek, D. K., "Iteration in engineering design: inherent and unavoidable or product of choices made?" in International Design Engineering Technical Conferences and Computers and Information in Engineering Conference, ASME, 2003, pp. 669-674. https://doi.org/10.1115/detc2003/dtm-48662

[13] D. Dörner, and J. Funke, "Complex Problem Solving: What It Is and What It Is Not," Frontiers in Psychology, vol. 8, pp. 1153, July 2017

[14] L. Finlay, "Reflecting on 'reflective practice," Practice-based Professional Learning Centre, The Open University. PBPL Paper 52. Jan. 2008.

[15] J. Biggs, "Enhancing teaching through constructive alignment," Higher education, vol. 32, no. 3, pp. 347-364, October 1996. https://doi.org/10.1007/bf00138871

[16] B. Gillie, Reflective Practice: Writing and Professional Development 3rd ed. Los Angeles: Sage Publications. 2010.

[17] J. J. Loughran, "Effective reflective practice: In search of meaning in learning about teaching." Journal of Teacher Education, vol. 53, no. 1, pp. 33-43, January 2002. https://doi.org/ $\underline{10.1177 / 0022487102053001004}$

[18] J. Driscoll, "Reflective practice for practise," Senior Nurse, vol. 14, no. 1, pp. 47 -50, February 1994

[19] G. Rolfe, D. Freshwater, M. Jasper, Critical Reflection In Nursing And The Helping Professions: A User's Guide. Basingstoke: Palgrave Macmillan, 2001.

[20] C. Johns, "Framing learning through reflection within Carper's fundamental ways of knowing in nursing". Journal of Advanced Nursing, Vol. 22, no. 2, pp. 226-234, August 1995. https://doi.org/10.1046/j.1365-2648.1995.22020226.x

[21] J. D. Bain, R. Ballantyne, C. Mills, N. C. Lester, Reflecting On Practice: Student Teachers' Perspectives, Post Pressed: Flaxton, Queensland, 2002.

[22] G. Gibbs, Learning by doing: A guide to teaching and learning methods. Further Education Unit, 1988.

[23] R. M. Felder and R. Brent, Teaching and Learning STEM: A Practical Guide, San Francisco CA: John Wiley \& Sons, 2016, pp. 240-241.

[24] Engineering Without Borders - Canada. 2013 Failure Reports. Retrieved 2 March, 2020 from http://blogs.ewb.ca/failure2013/

[25] Engineering Without Borders - Canada. 2017 Failure Reports. Retrieved 2 March, 2020 from https://www.ewb.ca/wp-content/uploads/2018/08/EWB_FAILURE-REPORT_EN_0 3-08-2018-pages.pdf, https://doi.org/10.18411/d-2016-154

[26] M. Kapur, "Learning from productive failure," Learning: Research and Practice, vol. 1, no. 1, pp. 51-65, April 2015.

[27] S. G. Chowrira, K. M. Smith, P. J. Dubois, I. Roll, I. "DIY productive failure: boosting performance in a large undergraduate biology course," npj Science of Learning, vol. 4, no. 1, pp. 1-8, March 2019. https://doi.org/10.1038/s41539-019-0040-6

[28] J. Moon, "Getting the measure of reflection: considering matters of definition and depth", Journal of Radiotherapy and Practice, vol. 6, no. 4, pp. 191-200, 2007. https://doi.org/10.1017/s1460396907006188

[29] N. R. Tague. (2004). Fishbone Diagram [Online]. Available: https://asq.org/quality-resources/fishbone

[30] C. Argyris, Chris. "Double loop learning in organizations." Harvard Business Review vol. 55, no. 5, pp. 115-125, October 1977. 


\section{$7 \quad$ Author}

Ahmad Salahuddin Mohd Harithuddin is a senior lecturer at the Department of Aerospace Engineering, Universiti Putra Malaysia (UPM). He received his PhD in Aerospace Engineering from RMIT University. He is currently the Academic Coordinator for the Bachelor of Aerospace Engineering (with Honours) at the University. He is a member of the Innovation in Teaching and Learning Committee at the Centre of Acedemic Development, UPM. His other research areas include space systems and airship technology.

\section{Appendix}

An analytic rubric is developed to assess the performance of the students in Failure Report writing. Four criteria are defined: Failure Description, Reflection Writing, 'Blame Game', and Length of Report. For each criterion, three levels are defined: Beginning (lowest), Emerging, and Demonstrating (highest).

Table 4. Failure Report Rubric

\begin{tabular}{|l|l|l|l|}
\hline & \multicolumn{1}{|c|}{ Beginning } & \multicolumn{1}{c|}{ Emerging } & \multicolumn{1}{c|}{ Demonstrating } \\
\hline $\begin{array}{l}\text { Description of } \\
\text { Failure }\end{array}$ & $\begin{array}{l}\text { The actual failure is not } \\
\text { clearly stated. Writing is } \\
\text { more akin to a complain ra- } \\
\text { ther that a story. }\end{array}$ & $\begin{array}{l}\text { The failure is clearly de- } \\
\text { scribed and the way forward } \\
\text { is clear. Understand how } \\
\text { one can learn from experi- } \\
\text { ence. }\end{array}$ & $\begin{array}{l}\text { The failure is clearly de- } \\
\text { scribed. } \\
\text { Clear on why and how one } \\
\text { can learn from failure. } \\
\text { Points are explained effec- } \\
\text { tively in a few sentences. }\end{array}$ \\
\hline $\begin{array}{l}\text { Reflection } \\
\text { Writing }\end{array}$ & $\begin{array}{l}\text { Follows the Gibbs Cycle } \\
\text { worksheet instruction to a } \\
\text { T. }\end{array}$ & $\begin{array}{l}\text { Used the Gibbs Cycle work- } \\
\text { sheet only as a general } \\
\text { guide for reflection writing. }\end{array}$ & $\begin{array}{l}\text { Does not need instruction or } \\
\text { guide to write a reflection. }\end{array}$ \\
\hline 'Blame game' & $\begin{array}{l}\text { Elements of blame exist in } \\
\text { the story. }\end{array}$ & $\begin{array}{l}\text { Little elements of blame } \\
\text { still exist in the story though } \\
\text { not obvious. }\end{array}$ & $\begin{array}{l}\text { No elements of blame in the } \\
\text { story. }\end{array}$ \\
\hline Report Length & $\begin{array}{l}\text { Too short }(<250 \text { words }) \text { or } \\
\text { too long }(>500 \text { words). }\end{array}$ & Between 300-500 words. & $\begin{array}{l}\text { Effectively written between } \\
\text { 350-400 words. }\end{array}$ \\
\hline
\end{tabular}

Article submitted 2021-05-26. Resubmitted 2021-07-05. Final acceptance 2021-07-05. Final version published as submitted by the authors. 